\title{
ESTRATÉGIAS DE INOVAÇÃO EM CERVEJARIAS ESPECIAIS DA REGIÃO METROPOLITANA DE BELO HORIZONTE (MG)
}

\section{INNOVATION STRATEGIES IN SPECIAL BREWERS IN THE METROPOLITAN REGION OF BELO HORIZONTE (MG)}

\author{
João Francisco Sarno Carvalho \\ IFNMG - Instituto Federal do Norte de Minas Gerais \\ jfsarcar@gmail.com \\ Márcia Siqueira Rapini \\ CEDEPLAR - UFMG - Universidade Federal de Minas Gerais \\ msrapini@cedeplar.ufmg.br \\ Giovani Brandão Mafra de Carvalho \\ UEFS - Universidade Estadual de Feira de Santana - BA \\ brandao.phd@gmail.com
}

Submissão: $11 / 05 / 2021$ Aprovação: 29/12/2021

\section{RESUMO}

Este artigo versa sobre inovações existentes nas cervejarias especiais da região metropolitana de Belo Horizonte. Com o advento da produção de cervejas especiais, buscou-se compreender as inovações geradas pelo setor e também quais estratégias de inovação são utilizadas. Para galgar o objetivo proposto, o estudo utilizou-se de pesquisa qualitativa-descritiva com revisão de literatura, emprego de roteiro semiestruturado para entrevistas nas visitas às cervejarias e com análise de conteúdo para sistematização dos dados. Após a análise de dados, percebeu-se que ocorrem nas cervejarias as inovações incrementais. Além disso, as evidências apontaram que para buscar ampliar a fatia de mercado as cervejarias especiais lançam mão das estratégias de inovação passo a passo e orientada ao cliente, porém há o emprego da estratégia de inovação especializada em processo somente por aquelas cervejarias líderes de mercado que possuem maior alcance aos recursos financeiros, mão-de-obra especializada e maior capacidade produtiva.

Palavras-chave: Cervejarias Artesanais. Estratégias de Inovação. Inovação.

\begin{abstract}
This article is about existing innovations in special breweries in the metropolitan region of Belo Horizonte. With the advent of the production of special beers, we sought to understand the innovations generated by the sector and also which innovation strategies are used. To reach the proposed objective, the study used a qualitative-descriptive research with literature review, use of a semi-structured script for interviews during visits to breweries and with content analysis to systematize the data. After analyzing the data, it was noticed that incremental innovations occur in breweries. In addition, evidence pointed out that to seek to expand market share, special
\end{abstract}


breweries make use of step-by-step and customer-oriented innovation strategies, but there is the use of the process-specialized innovation strategy only by those market-leading breweries that have greater reach to financial resources, specialized labor and greater productive capacity.

Keywords: Craft Breweries. Innovation Strategies. Innovation.

\section{INTRODUÇÃO}

A cerveja possui importância social, histórica e econômica sendo "encarada de diferentes maneiras pelos sujeitos sociais" (GIORGI, 2015, p. 101). A bebida esteve presente nas grandes navegações, nos mosteiros católicos da Europa, nas revoluções, na industrialização e na consolidação do sistema capitalista de produção. No Brasil, a bebida tornou-se popular e está presente em um mercado que se posiciona entre os quatro maiores do mundo, situando-se na terceira posição na produção mundial de litros da bebida com 14 bilhões de litros produzidos (CERV Brasil, 2021). Além da grande produção da bebida, o mercado cervejeiro brasileiro mantém-se aquecido e em expansão com aumento no número de novas cervejarias registradas nos últimos dois anos, além do aumento da quantidade de novos produtos registrados (MARCUSSO; MULLER, 2019, 2020).

Em paralelo ao crescimento da produção de litros de cerveja, da diversificação dos rótulos produzidos e comercializados e da incorporação e da criação de novas marcas industrializadas, outro ramo do mercado cervejeiro também cresce e contribui para a diversificação do produto: a produção de cervejas especiais.

Dentro do mercado brasileiro de cervejas especiais, escolheu-se como cenário desse estudo a região metropolitana de Belo Horizonte (RMBH), formada por 34 municípios, pois se trata de uma região com indicadores econômicos e sociais relevantes e possui a presença de inúmeras cervejarias especiais. A RMBH abrange $26 \%$ da população de todo o estado, $40 \%$ do Produto Interno Bruto (PIB) e é a $3^{\mathrm{a}}$ maior região metropolitana do Brasil (PBH, 2018).

Outro aspecto relevante para a escolha da RMBH como pano de fundo para esse estudo se dá pela presença de 15 das 41 cervejarias especiais instaladas em Minas Gerais. Tal feito caracteriza a região como Cinturão da Cevada em Minas Gerais (AYER, 2017).

Essas cervejarias encontradas na RMBH mostram-se inovadoras e são crescentes em quantidade de registros de novos produtos. Os pedidos de registro de novas cervejas para o Ministério da Agricultura, Pecuária e Abastecimento (MAPA) aumentam a cada ano. Em 2018, o MAPA concedeu 6.800 registros para cervejas e chopes, sendo Minas Gerais o estado líder na quantidade de pedidos deferidos com 1.300 processos para novos produtos cervejeiros (cervejas e chopes) (MARCUSSO; MULLER, 2019). Na região metropolitana de Belo Horizonte, destaca-se o município de Nova Lima (MG) com 277 registros de novas cervejas em 2018, situando-se na $2^{a}$ posição no Brasil. Além disso, Nova Lima também se destaca na densidade cervejeira com uma cervejaria para cada 4.000 habitantes (MARCUSSO, MULLER, 2020).

Dito isso, esse artigo justifica-se uma vez que as cervejarias artesanais inovam e crescem e os olhares para suas inovações tecnológicas produzidas e para as suas estratégias de inovação são necessários, uma vez que há escassez de pesquisas dentro da área de gestão que versem sobre a temática. A contribuição aqui proposta, traz essa reflexão e pode auxiliar para descortinar a problemática de como as inovações são propostas e como as estratégias de inovação são estruturadas no setor de cervejas especiais. Sendo assim, essa pesquisa busca responder à seguinte pergunta problematizadora: quais são as estratégias de inovação adotadas pelas cervejarias artesanais da região metropolitana de Belo Horizonte?

De modo geral, objetiva-se a partir desse artigo, identificar as estratégias de inovação das cervejarias especiais da RMBH a partir de uma pesquisa qualitativa. Assim sendo, o estudo 
em questão encontra-se dividido em cinco seções, sendo que nessa primeira seção, é apresentada a introdução; na segunda seção são trazidos para a discussão os aspectos teóricos que fundamentam o estudo; na terceira seção são descritos os procedimentos metodológicos; na quarta seção apresentam-se os resultados e as análises de dados; e, por fim, na quinta seção, são apresentadas as considerações finais desse estudo.

\section{REFERENCIAL TEÓRICO}

A presente seção está dividida em três subseções, organizadas a partir do levantamento das principais abordagens discutidas nesse estudo. Na primeira subseção há um recorte teórico que apresenta uma discussão sobre o surgimento dos estudos em inovação até a discussão que apresenta as estratégias de inovação. Em seguida, são apresentadas as estratégias de inovação no setor de baixa tecnologia, setor esse que engloba as cervejarias especiais aqui estudadas. $\mathrm{E}$, por fim, é trazida uma discussão que apresenta o histórico da cerveja e o surgimento do movimento de cervejarias especiais, com enfoque para o mercado brasileiro.

\subsection{INOVAÇÕES: DA INTRODUÇÃO AO TEMA ÀS ESTRATÉGIAS DE INOVAÇÃO}

As teorias de inovação foram discutidas por inúmeros teóricos subsequentes a Schumpeter e, a partir das modificações de mercado, passamos a ter os autores neoschumpterianos, que adotaram novas perspectivas para discutir a temática da inovação, bem como seus determinantes. Para a compreensão da proposta aqui feita, as definições de inovação do Manual de Oslo (1997) e Kline e Rosemberg (1986) fazem-se importantes. Sendo assim, uma inovação pode ser considerada como

a implementação de um produto (bem ou serviço) novo ou significativamente melhorado, ou um processo, ou um novo método de marketing, ou um novo método organizacional nas práticas de negócios, na organização do local de trabalho ou nas relações externas (MANUAL DE OSLO, 1997, p. 55).

Kline e Rosenberg (1986) trouxeram contribuições para as teorias neo-schumpterianas e discutiram que a inovação é resultado de um processo de interação entre o conhecimento gerado e as oportunidades de mercado. Trata-se de um processo não sequencial, que envolve vários subprocessos, interações e realimentações (feedback) para a solução de problemas surgidos ao longo do processo de inovação. Dosi e Nelson (1994), também na mesma linha neo-schumpeteriana, mostram que a inovação se refere a: busca, descoberta, experimentação, desenvolvimento, imitação e adoção de novos produtos, novos processos e nova organização.

Entretanto, para a discussão aqui proposta faz-se necessário definir muito bem o termo inovação para entendê-lo no contexto, em que o processo de fazer de uma oportunidade uma nova ideia e colocá-la no mercado são o cerne da discussão (TIDD; BESSANT; PAVITT, 2005).

Para além desses conceitos apresentados, a inovação também pode ser classificada em dois tipos: incremental e radical (FREEMAN; SOETE, 2008). Quando ocorrem pequenas alterações em produtos através do conhecimento disponível, chamamos as inovações de incrementais (TIRONI; CRUZ, 2008). Já a inovação radical é aquela que "baseada em uma novidade tecnológica ou mercadológica, leva à criação de um novo mercado, podendo (ou não) acarretar a descontinuidade do mercado existente". (TIRONI; CRUZ, p. 8, 2008).

Outra classificação de inovação que aqui tem importância é a dada pelas quatro dimensões da inovação abordados por Tidd e Bessant (2015). Nessa proposta, as inovações incrementais e radicais ainda podem ser subdivididas nos 4P's da inovação, que são: a) Inovação de produto: mudanças nos produtos e serviços oferecidos por uma empresa; b) Inovação no processo: mudanças na forma como os produtos e serviços são entregues; c) Inovação de posição: mudanças no contexto em que produtos e serviços são introduzidos no mercado; d) 
Inovação de paradigma: mudanças nos modelos mentais subjacentes que orientam o que a empresa faz (TIDD; BESSANT, 2015). A figura 01, a seguir, ilustra essa tipologia:

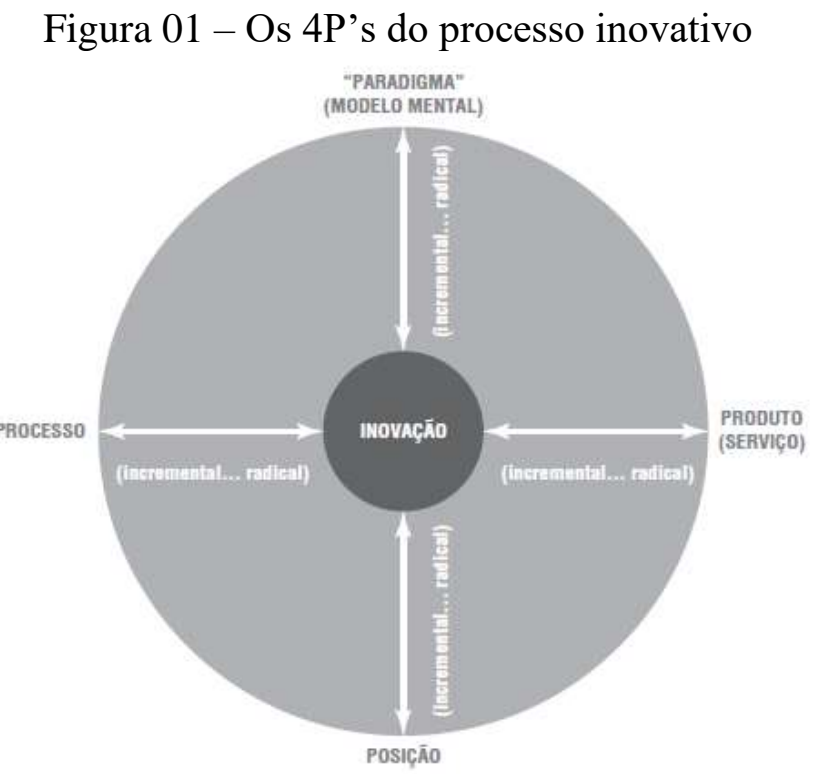

Fonte: Tidd; Bessant (2015, p. 25).

Nesse estudo, de modo específico, as inovações abordadas devem ser compreendidas a partir da ótica da gestão da inovação, no campo empresarial, o qual compreende as cervejarias especiais que, na maioria dos casos, se enquadram como micro e pequenas empresas.

Sawhney, Wolcott e Arroniz (2006, p. 76) definem a inovação empresarial como "a criação de um novo valor substancial para os clientes e para a empresa, alterando, de forma criativa, uma ou mais dimensões do sistema de negócios". Entretanto, as inovações não ocorrem de modo semelhante nas empresas, uma vez que o tamanho das empresas importa, a capacidade de acesso à recursos financeiros, humanos e tecnológicos. Por isso, as estratégias de inovação realizadas pelas empresas são diferentes. Na próxima subseção, serão abordadas as estratégias de inovação no setor de baixa tecnologia que engloba as empresas do setor cervejeiro.

\subsection{ESTRATÉGIAS DE INOVAÇÃO NO SETOR DE BAIXA TECNOLOGIA}

A OCDE organizou o setor produtivo em categorias de indicadores de intensidade de Pesquisa e Desenvolvimento (P\&D). Essa proposição prevê uma hierarquia entre setores com maiores ou menores intensidades em P\&D.

O setor de alimentos e bebidas alcoólicas caracteriza-se como um setor de média-baixa tecnologia (MORCEIRO, 2018), sendo as empresas "expressivas na geração de PIB ou de emprego" (MORCEIRO, 2019, p. 10).

Essas empresas classificadas como "low-tech" também inovam, entretanto, as inovações nessas empresas possuem particularidades que foram descritas por Tunzelmann e Acha (2005) e Pavitt (1984). Segundo esses autores, as inovações no setor ocorrem nos processos ou ainda são conduzidas por terceiros (fornecedores) que empurram tecnologias, insumos ou materiais, sendo os investimentos em P\&D baixos ou inexistentes (TUNZELMANN; ACHA, 2005; PAVITT, 1984). As empresas inovam em produtos com ocorrência de inovações incrementais ou com a aquisição de novas máquinas e a transferência de tecnologia de algum membro da cadeia produtiva (fornecedor, cliente, stakeholders).

As maneiras de inovar das empresas low-tech são particulares e diferem dos setores mais intensivos em tecnologia. Isso se sustenta porque as empresas low-tech possuem: a) pouca 
estruturação e sistematização dos processos de inovação; b) escassez de recursos para o desenvolvimento de produtos; d) deficiência na qualificação profissional dos profissionais envolvidos com a inovação; e) inovações limitadas aos processos, design e inovações incrementais; e, por fim, f) grande dependência dos fornecedores de máquinas e equipamentos e da matéria-prima como direcionadores de inovações (HIRSCH-KREINSEN, et al., 2003).

As estratégias de inovação podem ser vistas como "combinações das preferências, atividades e capacitações das empresas para gerar e difundir diversos tipos de inovação e para lidar com as incertezas tecnológicas e as demandas de mercado" (COSTA, FILHA, GUIDOLIN, 2011, p. 408). Dentro desse escopo, Hirsch-Kreinsen (2008) identificaram três estratégias de inovação adotadas pelas empresas de baixa e média tecnologia (BMT) que são: 1) passo a passo; 2) orientada ao cliente; 3) especializada em processo. Nessas estratégias, prevalecem as inovações incrementais e arquiteturais (COSTA; FILHA; GUIDOLIN, 2011). O quadro 1 sumariza as características das estratégias de inovações presentes nas empresas de baixa e média tecnologia.

Quadro 1 - Tipos de estratégias de inovações nas empresas de baixa e média tecnologia

\begin{tabular}{c|c|c|c}
\hline Objetivo principal & Passo a Passo & Orientada ao cliente & $\begin{array}{c}\text { Especializada em } \\
\text { processo }\end{array}$ \\
\hline Objetivo principal & $\begin{array}{c}\text { Desenvolvimento } \\
\text { incremental do produto }\end{array}$ & $\begin{array}{c}\text { Melhorar a posição de } \\
\text { mercado; criar mercados }\end{array}$ & $\begin{array}{c}\text { Otimização de } \\
\text { tecnologias de processos }\end{array}$ \\
\hline Exemplo & $\begin{array}{c}\text { Empresas fornecedoras } \\
\text { da indústria automotiva }\end{array}$ & $\begin{array}{c}\text { Indústrias da moda e do } \\
\text { vestuário orientadas para } \\
\text { a moda }\end{array}$ & $\begin{array}{c}\text { Manufatura de papel e } \\
\text { processamento de } \\
\text { alimentos }\end{array}$ \\
\hline Principais condições & $\begin{array}{c}\text { Empresas com } \\
\text { segmentos de mercado } \\
\text { relativamente estáveis }\end{array}$ & $\begin{array}{c}\text { Amplo conjunto de } \\
\text { empresas com condições } \\
\text { de mercado turbulentas }\end{array}$ & $\begin{array}{c}\text { Empresas com processos } \\
\text { de produção } \\
\text { automatizados e } \\
\text { integrados }\end{array}$
\end{tabular}

Fonte: Hirsch-Kreinsen (2008, p. 27).

Hirsch-Kreinsen (2008) e Costa, Filha e Guidolin (2011) definem as estratégias de inovação das empresas de baixa e média tecnologia em três tipos, que são:

a) Passo a Passo: é a estratégia que trata do desenvolvimento contínuo de produtos conhecidos. Sendo assim, os componentes dos produtos são melhorados e modificados. Os mercados são bem definidos, os produtos são bem estabelecidos e frequentemente padronizados, a tecnologia de produção é eficiente e o preço é o principal fator de competição. Nesse tipo de produção, a mudança é complexa. Essa estratégia tem característica típica da inovação incremental (HIRSCH-KREINSEN; 2008, COSTA, FILHA, GUIDOLIN, 2011).

b) Orientada ao cliente: nessa estratégia há a busca por inovações relacionadas a assegurar e melhorar a situação de mercado da empresa. São fabricantes cujo desenvolvimento de produtos é atrelado à antecipação dos ciclos de moda e nos quais as linhas existentes de produtos demandam uma variação mais ou menos contínua. Pode-se entender essa estratégia como um exemplo das inovações arquiteturais, pois é baseada no rearranjo de componentes e unidades para fornecer novos produtos, que não apenas atendam a necessidades específicas de clientes, mas também abram novos segmentos de mercado (HIRSCH-KREINSEN; 2008, COSTA, FILHA, GUIDOLIN, 2011).

c) Especialização em processos: nessa estratégia os esforços de inovação são direcionados para as estruturas de processos organizacionais e técnicos, que podem empregar tecnologias de produção ultramodernas, automatizadas e intensivas em capital. Essa estratégia 
compreende não apenas a produção automatizada de alta tecnologia, mas também técnicas simples que estão, constantemente, sendo "aprimoradas" (HIRSCH-KREINSEN; 2008, COSTA, FILHA, GUIDOLIN, 2011). Ela é constituída tanto pela otimização técnica e organizacional dos processos de produção existentes quanto pela sua reestruturação na base das tecnologias existentes - ou seja, há características de inovações incrementais e arquiteturais (HIRSCH-KREINSEN; 2008, COSTA, FILHA, GUIDOLIN, 2011).

A próxima subseção abordará sobre o surgimento da cerveja com o seu histórico até o desembarque no Brasil com a popularização da bebida e o surgimento do movimento de cervejarias especiais na região.

\subsection{CERVEJAS: HISTÓRICO DA BEBIDA E O SURGIMENTO DAS CERVEJARIAS ESPECIAIS}

O processo produtivo da cerveja é antigo e percorre toda a história. A bebida esteve presente nos feudos, nos monastérios e nas grandes navegações até chegar à atualidade, em que pode ser encontrada em todo o mundo com uma diversidade de sabores, nacionalidades e rótulos.

Registros históricos dizem que a cerveja é uma bebida milenar, que começou a ser produzida por povos entre os anos de 4000 e 5000 antes de Cristo (TORNIC, 1986). O povo sumério detém o registro da primeira produção da cerveja assim como assírios e babilônios. A bebida produzida pelos sumérios era elaborada com água, grãos moídos e que, com o cozimento, era consumida como "pão líquido". Tschop (2001) mostra que essa bebida era precursora da atual cerveja consumida no mundo. Há ainda quem credite à criação da cerveja às mulheres que, na Mesopotâmia, eram responsáveis pela produção dos alimentos da casa e tratavam do armazenamento e do cozimento de grãos (BELTRAMELLI, 2014).

No Brasil, a bebida chegou com a invasão holandesa no século XVII (SANTOS, 2003). Porém, com a expulsão dos holandeses a produção só retornou com o desembarque da família Real em 1808, já que a bebida era a preferida de Dom João VI (GIORGI, 2015). A cerveja embora fabricada por muito tempo na base do empirismo, popularizou-se no Brasil. No século XIX, a bebida começou a ser feita com técnicas, processos e receitas e no século XX, tornouse industrializada (CRUZ, 2007). Desde a chega da bebida no Brasil até o início dos anos 2000 houveram ciclos da bebida no país.

Carvalho (2020) define esses ciclos em cinco, que são: a produção de uma bebida fermentada à base de mandioca chamada cauim pelos índios brasileiros; a chegada da família Real em 1808, a importação da bebida e o início de pequenas produções empíricas de cerveja; o desenvolvimento das cervejarias como a Companhia Antarctica Paulista e a Manufactura de Cerveja Brahma Villiger e Companhia, que posteriormente se fundiram formando a AmBev; o surgimento de acordos comerciais e fusões que tornaram a AmBev a maior empresa transnacional do setor de bebidas alcoólicas do mundo e o último estágio chamado de renascimento cervejeiro, com a expansão e consolidação das cervejarias especiais (CARVALHO, 2020).

O movimento de cervejarias especiais no Brasil surgiu na segunda metade da década de 1980, com influências das escolas cervejeiras europeias e norte americanas e estabeleceram-se nas regiões do Sul e do Sudeste (MORADO, 2009). Giorgi (2015) lembra que no Brasil diversas microcervejarias abriram suas portas com objetivo de levar aos consumidores uma proposta diferenciada de cervejas, trazendo a importância dessa bebida como um alimento e não somente uma simples bebida alcoólica.

Minas Gerais destaca-se no Brasil, especialmente a região metropolitana de Belo Horizonte, pela concentração de boa parte das cervejarias especiais de todo o estado (MARCUSSO; MULLER, 2020). Já a capital mineira, Belo Horizonte, possui cerca de 28 bares 
a cada quilômetro quadrado e um total de 9.500 estabelecimentos comerciais destinados à comercialização de bebidas alcoólicas (PBH, 2018).

O Ministério da Agricultura Pecuária e Abastecimento (MAPA) registra entre os anos de 1999 e 2019, um crescimento de cervejarias registradas no Brasil de 33 para 1209, evidenciando um crescimento da quantidade de cervejarias formalizadas (MARCUSSO; MULLER, 2020). Desse modo, Giorgi (2015) constatou que há, no Brasil, um movimento que busca ressignificar a cerveja no país, tornando-a produto de distinção, com qualidade e identidade. Esse fenômeno também é explicado por Toro-González (2015) que diz que na América Latina havia espaço para cervejas diferenciadas (especiais) uma vez que as cervejas produzidas na região eram feitas por cervejarias multinacionais e tinham características produtos de massa e sem distinção. A próxima seção trará a metodologia de pesquisa empregada nesse estudo.

\section{METODOLOGIA DE PESQUISA}

Nessa pesquisa, a opção se deu por uma metodologia de viés qualitativo-descritivo foi a escolhida para investigar o objeto de pesquisa aqui definido. Optou-se por esse tipo de metodologia uma vez que os estudos qualitativos-descritivos trazem à discussão outras variáveis de análise que incorporem as relações humanas, sejam elas formais, informais, individuais ou coletivas. Há, então, uma tentativa de promoção de outras técnicas metodológicas não tradicionais ou consolidadas nas reflexões sobre inovação. Yin (2016) recorda que a abordagem de pesquisa qualitativa é aquela em que a pesquisa não se caracteriza como um diário ou uma narrativa, mas, sim, como um desejo de explicar acontecimentos da vida real com o auxílio de conhecimentos emergentes ou existentes.

Sobre essa opção, Carvalho, Oliveira e Godinho (2019) ressaltam que, na atualidade, é necessário tentar outras entradas além daquelas que já estão postas nas ciências para a obtenção de respostas aos anseios sociais, além de produzir e difundir novas tecnologias e inovações. Em um primeiro momento, realizou-se pesquisa bibliográfica nas bases de dados dos grupos de pesquisa do Conselho Nacional de Desenvolvimento Científico e Tecnológico (CNPq), do Google Acadêmico e da A Coordenação de Aperfeiçoamento de Pessoal de Nível Superior (CAPES) na busca por estudos que versassem sobre inovação tecnológica, estratégias de inovação e cervejarias artesanais. Com os resultados encontrados, estruturou-se o referencial teórico que sustenta a discussão aqui proposta e percebeu-se uma lacuna: a falta de um trabalho que buscasse compreender quais são as estratégias de inovações tecnológicas no setor de bebidas alcoólicas, de modo específico, no setor cervejeiro.

No segundo momento da pesquisa, foram realizadas visitas em seis cervejarias localizadas na região metropolitana de Belo Horizonte (MG), nos municípios de Ribeirão das Neves, Nova Lima, Belo Horizonte e Vespasiano. E a partir dessas visitas, coletou-se informações com a aplicação de roteiro de entrevista aos gestores e mestres cervejeiros responsáveis pela produção das cervejarias. O roteiro de entrevista teve característica semiestruturada, uma vez que nessa técnica de pesquisa, durante a condução do estudo podem ser inseridas ou retiradas questões.

$\mathrm{Na}$ elaboração do roteiro foram utilizadas questões oriundas dos estudos de Ferreira (2010), Almeida (2014) e Back (2015) além da Pesquisa de Inovação (PINTEC) do Instituto Brasileiro de Geografia e Estatística (IBGE). Mas para além dos roteiros semiestruturados préestabelecidos, diálogos informais também ocorreram. A opção pelo uso de roteiro de entrevista se deu porque quando há uma pesquisa qualitativa-descritiva, os dados rejeitam a expressão numérica e aparecem sob a forma de transcrições de entrevistas, anotações de campo, fotografias e vários tipos de documentos (GODOY, 1995).

As seis cervejarias pesquisadas foram visitadas no período de março de 2019 a março de 2020 e todas encontram-se instaladas na região metropolitana de Belo Horizonte (MG). A 
condução da pesquisa ocorreu por agendamento prévio e os pesquisadores foram recebidos pelos proprietários e/ou mestres cervejeiros nas dependências das cervejarias. Os dados foram coletados com gravador de áudio e aparelho smartphone. Por questões éticas, os nomes das cervejarias foram substituídos por cervejarias A, B, C, D, E e F, bem como os nomes de todas as pessoas envolvidas na pesquisa. Todos os participantes assinaram um termo de Termo de Consentimento Livre e Esclarecido (TCLE).

O quadro 2 abaixo apresenta as seis cervejarias pesquisadas com a indicação da capacidade produtiva (em litros), quantidade de funcionários, tempo de existência, tipos de cervejas produzidos e se possui uma área/setor específico para o desenvolvimento de novos produtos.

Quadro 2 - Apresentação das características das cervejarias visitadas

\begin{tabular}{|c|c|c|c|c|c|c|}
\hline Cervejaria & $\begin{array}{c}\text { Capaci } \\
\text { dade } \\
\text { Produti } \\
\text { va (em } \\
\text { litros) }\end{array}$ & $\begin{array}{c}\mathrm{N}^{\mathrm{o}} \text { de } \\
\text { funcionári } \\
\text { os }\end{array}$ & $\begin{array}{l}\text { Tempo de } \\
\text { existência }\end{array}$ & $\begin{array}{l}\text { Tipos de } \\
\text { cervejas } \\
\text { produzidas }\end{array}$ & $\begin{array}{c}\text { Área/setor } \\
\text { específico } \\
\text { para o } \\
\text { desenvolvime } \\
\text { nto de novos } \\
\text { produtos }\end{array}$ & Entrevistado \\
\hline A & 30.000 & 30 & $\begin{array}{l}\text { Desde } \\
2004\end{array}$ & $\begin{array}{c}\text { Pilsen, Pale } \\
\text { Ale, IPA, } \\
\text { Dry Stout, } \\
\text { Weiss, Fruit } \\
\text { Bier, Tripel. }\end{array}$ & Não & $\begin{array}{c}\text { Mestre } \\
\text { cervejeiro/Proprie } \\
\text { tário }\end{array}$ \\
\hline B & 26.000 & 20 & $\begin{array}{c}\text { Desde } \\
2015\end{array}$ & $\begin{array}{c}\text { Lager, } \\
\text { Weizen, } \\
\text { Schwarz, } \\
\text { Pilsen, IPA. }\end{array}$ & Não & Mestre cervejeiro \\
\hline $\mathrm{C}$ & 6.000 & 2 & $\begin{array}{l}\text { Desde } \\
2015\end{array}$ & $\begin{array}{c}\text { IPA, Pilsen, } \\
\text { APA, } \\
\text { Weiss. }\end{array}$ & Não & $\begin{array}{c}\text { Mestre } \\
\text { cervejeira/Proprie } \\
\text { tária }\end{array}$ \\
\hline $\mathrm{D}$ & 60.000 & 6 & $\begin{array}{l}\text { Desde } \\
2015\end{array}$ & $\begin{array}{l}\text { IPA, APA, } \\
\text { Pilsen, } \\
\text { Weiss. }\end{array}$ & Não & Mestre cervejeiro \\
\hline $\mathrm{E}$ & $\begin{array}{c}400.00 \\
0\end{array}$ & 65 & $\begin{array}{c}\text { Desde } \\
1997\end{array}$ & $\begin{array}{c}\text { Hefe, } \\
\text { Golden Ale, } \\
\text { Dunkel, } \\
\text { IPA, APA, } \\
\text { Tripel, } \\
\text { Double } \\
\text { IPA, Stout, } \\
\text { Pilsen. }\end{array}$ & Não & $\begin{array}{c}\text { Mestre } \\
\text { cervejeiro/Proprie } \\
\text { tário }\end{array}$ \\
\hline $\mathrm{F}$ & $\begin{array}{c}600.00 \\
0\end{array}$ & 68 & $\begin{array}{c}\text { Desde } \\
2000\end{array}$ & $\begin{array}{c}\text { Lager, } \\
\text { Dubbel, } \\
\text { IPA, APA, } \\
\text { Tripel, } \\
\text { Quadruppel. }\end{array}$ & Sim & $\begin{array}{c}\text { Mestre Cervejeiro } \\
\text { e Analista de } \\
\text { Marketing }\end{array}$ \\
\hline
\end{tabular}

Fonte: dados da pesquisa (2021). 
Todas as entrevistas foram realizadas no ambiente produtivo da cerveja com objetivo de evitar o "estranhamento" da relação entre pesquisador e pesquisado. Buscou-se deixar os entrevistados à vontade no ambiente em que estão acostumados a atuar. De maneira geral, as entrevistas foram utilizadas como um meio para encontrar respostas que contribuam na compreensão de como se dão os processos que levam para o surgimento das inovações nas cervejarias especiais pesquisadas. Buscou-se, a partir das perguntas inseridas no roteiro de entrevista, abordar, em blocos de questões, os seguintes questionamentos: como se dão os processos criativos das cervejas especiais? Há influência de consumidores, concorrentes e parceiros do negócio (stakeholders) nos processos inovativos? O que é inovação para essa cervejaria? Essa cervejaria é inovadora? Como essa cervejaria inova?

Apresentou-se também aos seis cervejeiros/proprietários as classificações de estratégias de inovação conforme sugerido por Morceiro $(2018$; 2019) e solicitou-se que estes respondessem em qual estratégia a sua empresa mais se adequa. E, por fim, buscou-se ainda, compreender quais meios a cervejaria utiliza para enxergar o mercado cervejeiro na atualidade.

Todas as informações coletadas foram transcritas e analisadas a partir das técnicas de análise de conteúdo propostas por Carvalho (2020), em que se sugere agrupar os conteúdos das falas por tópicos e assuntos. Moraes (1999) também ensina que a análise de conteúdo pode ser utilizada com o objetivo de descrever e interpretar os dados provenientes de diferentes tipos de documentos oriundos de comunicação verbal ou não-verbal. Nesse sentido, nesse estudo foram extraídos os sentidos das respostas obtidas no roteiro de entrevistas e nos diálogos informais que ocorreram nas visitas realizadas às cervejarias. Na próxima seção, são apresentadas as discussões com os dados coletados nesse estudo e, posteriormente, as considerações finais.

\section{DISCUSSÕES}

Essa seção tem como objetivo apresentar os tipos de inovação presentes nas cervejarias especiais da região metropolitana de Belo Horizonte (RMBH), bem como as estratégias de inovação que são utilizadas por essas cervejarias. Nesse sentido, o trecho discorreu, na primeira etapa, sobre os tipos de inovação que são encontrados nessas cervejarias, classificando-as conforme as propostas de Freeman e Soete (2008) e Tidd e Bessant (2015). Por fim, são apresentadas as estratégias de inovação encontradas conforme a classificação proposta pela OCDE e encontrada nos estudos de Hirsch-Kreinsen (2008) e Costa, Filha e Guidolin (2011).

Após a coleta e a sistematização dos dados, deu-se, no primeiro momento um olhar sobre as inovações realizadas pelas cervejarias na busca por compreender quais são os tipos de inovação presentes. Nesse sentido, os dados evidenciaram que todas as cervejarias visitadas (A a F) inovam de maneira incremental, a partir da criação de novas cervejas que oferecem diferentes sabores para o mercado consumidor.

Essas inovações ocorrem por alterações no processo produtivo, com a introdução de novos e diferentes ingredientes, modificação na fermentação com o emprego de diferentes técnicas. Entretanto, percebeu-se que as técnicas empregadas, ou em outas palavras, o saber fazer das cervejas especiais é o mesmo para todas as cervejarias. Existem, nesse sentido, pequenas alterações nas etapas de produção com a inclusão de técnicas de fermentação distintas e outros ingredientes, tais como frutas e especiarias. Porém, a técnica de produção cervejeira é a mesma em todas as cervejarias respeitando as etapas tradicionais apontadas por Rogerio e Moretti (2008) que ocorrem com a produção do mosto, fermentação, maturação, carbonatação, pasteurização e análises finais.

Sendo assim, as evidencias apontaram para a presença de inovações incrementais, aquelas que em que há pequenas alterações nos produtos, tornando-os melhores (FREEMAN; SOETE, 2008). Essas inovações incrementais foram relatadas pelos cervejeiros nas respostas das questões apresentadas nas entrevistas. $\mathrm{O}$ cervejeiro $\mathrm{A}$ afirma que as cervejarias especiais são criativas e diz que "o nosso mercado é muito criativo, especialmente em Minas Gerais. Aqui 
somos tratados como maior polo de inovação e criatividade na criação de novas cervejas [...] buscamos sempre oferecer produtos novos para os clientes". No mesmo caminho o cervejeiro $B$ indicou que

inovar e criar novas cervejas é um processo natural nesse mercado de Minas Gerais e de $\mathrm{BH}$, sabe? A gente sempre busca incluir ingredientes novos para agradar os clientes. Temos cervejas autorais novas com frutas bem mineiras como jabuticaba, por exemplo.

Há ainda, a partir das evidências, a presença de inovações de produto e de processo em todas as cervejarias visitadas, uma vez que há criação de novos rótulos, utilização de diferentes garrafas, introdução de novos insumos e técnicas alternativas de fermentação. Dois cervejeiros entrevistados relataram aos pesquisadores que buscam inovar a partir de novas técnicas de fermentação e sobre isso os cervejeiros D e F disseram que "nós buscamos a novidade sempre, criamos técnicas de fermentação novas, testamos e se der certo, introduzimos no mercado esse produto com esse diferencial”. Já o cervejeiro A foi além e afirmou que

minha cervejaria é extremamente inovadora. Criamos uma máquina própria de torrefação do malte e além disso, somos a única que temos uma cerveja que refermenta na própria garrafa ao som de canto gregoriano. O que deixa a cerveja única, com um sabor inigualável.

As estratégias de inovação do setor de baixa tecnologia aqui estudadas estão presentes em todas as cervejarias especiais. O quadro 3 ilustra os tipos de estratégia de inovação do setor de baixa tecnologia presentes nas cervejarias especiais da RMBH aqui estudadas. Quadro 3 - Estratégias de Inovação Presentes nas Cervejarias Estudadas

\begin{tabular}{c|c|c|c|c|c|c} 
Estratégia & \multicolumn{7}{c}{ Cervejaria } \\
\hline & $\mathrm{A}$ & $\mathrm{B}$ & C & D & E & F \\
\hline $\begin{array}{c}\text { Passo a } \\
\text { Passo }\end{array}$ & $\mathrm{X}$ & $\mathrm{X}$ & $\mathrm{X}$ & $\mathrm{X}$ & $\mathrm{X}$ & $\mathrm{X}$ \\
\hline $\begin{array}{c}\text { Orientada ao } \\
\text { Cliente }\end{array}$ & $\mathrm{X}$ & $\mathrm{X}$ & $\mathrm{X}$ & $\mathrm{X}$ & $\mathrm{X}$ & $\mathrm{X}$ \\
\hline $\begin{array}{c}\text { Especializada } \\
\text { em Processo }\end{array}$ & & & & $\mathrm{X}$ & $\mathrm{X}$ & $\mathrm{X}$ \\
\hline Fon Probord
\end{tabular}

Fonte: elaborado pelos autores (2021).

A estratégia passo a passo é aquela em que se desenvolve continuamente os produtos já conhecidos (COSTA, FILHA, GUIDOLIN, 2011), foi percebida em todos os casos (cervejarias A a F), uma vez que as cervejarias realizam inovações incrementais nos produtos com a criação de novos produtos, a inserção de novas garrafas e rótulos, a utilização de diferentes técnicas de fermentação, a busca pela melhoria da qualidade a cerveja vendida com objetivo de atrair um maior número de consumidores e assim potencializar a venda dos produtos. Esses aspectos foram percebidos em destaque nas falas do cervejeiro $\mathrm{C}$ que afirmou "nós tentamos sempre melhorar nossos produtos. Verificar as tendências dos mercados da Europa e dos Estados Unidos e inserir aqui, aprimorando nossas cervejas e ganhando o público". O cervejeiro A foi de encontro a essa ideia quando trouxe a percepção sobre a inovação na sua cervejaria e afirmou:

nós fomos os primeiros a trazer uma garrafa estilo de champanhe, inserimos no mercado esse novo tipo de embalagem e foi um sucesso. Depois seguimos nesse caminho e produzimos outra cerveja com a mesma embalagem, mas com um sabor frutado vindo da jabuticaba e com uma fermentação diferenciada. Nós estamos sempre tentando melhorar.

Já as estratégias orientadas aos clientes, que para Costa, Filha e Guidolin (2011) são aquelas que ocorrem quando as empresas buscam inovar para assegurar e melhorar a situação de mercado. No caso em questão, essas estratégias ocorrem em todas as cervejarias pesquisadas (A a F). 
Foram percebidas cervejarias que lançam produtos específicos para nichos como clientes celíacos e em necessidades de dietas especiais. Nesse caso ocorreram, por exemplo, os lançamentos de cervejas especiais sem glúten e cervejas low-carb para pessoas em dietas de restrições calóricas. Entretanto, essas cervejas são produzidas apenas pelas cervejarias E e F, uma vez que são cervejarias com maior capacidade produtiva, maior acesso à mão-de-obra especializada e com maior presença de mercado. Sobre essas cervejas especiais para dietas com restrições alimentares o cervejeiro E relata que

olha [...] nós inserimos no mercado uma cerveja mais leve, sabe? Tem muita gente nessa onda fitness que está procurando esse tipo de produto e nós não queríamos ficar de fora disso. Tem consumidor que não abre mão de tomar a sua cerveja mesmo quando está de dieta [...] e a gente percebeu aí uma oportunidade. Fizemos uma cerveja mais leve, testamos, ficou boa e o mercado gostou. Nós ainda estamos também fazendo agora uma sem glúten, foi pedido de consumidores nossos e estamos atendendo.

O cervejeiro E contribui na mesma linha quando diz que busca atender o cliente e fazer cervejas especiais que os clientes gostem e consumam. Ele diz que

a nossa empresa é voltada a fazer aquilo que o cliente gosta. Se hoje há uma percepção de que uma cerveja mais lupulada é melhor, nós vamos fazer e entregar para o cliente. O interessante é que nós temos um clube de assinatura em que nós podemos enviar todo mês cervejas novas para os clientes assinantes e testar com eles se os sabores agradam a partir das pesquisas de opinião que enviamos. Para nós isso é uma experiência muito rica.

De maneira geral, todas as cervejarias especiais estudadas apostam em cervejas especiais mais leves, ou ainda, com menor teor alcoólico para conquistar os consumidores que ainda estão na fase inicial de descoberta do mercado. Nesses sentidos captados, a estratégia orientada ao cliente é a que melhor explica os fenômenos encontrados.

Vale lembrar que as cervejarias especiais têm sido mais hábeis em responder às mudanças nos gostos dos consumidores. Essas cervejarias conseguem produzir produtos com diferenciação frente às de massa uma vez que "fornecem para um mercado mais exigente, podem se dar ao luxo de ser mais aventureiras nos estilos de cerveja que produzem, e isso amplia a competitividade, apesar de os preços serem mais altos" (CABRAS; HIGGINS, 2016, p. 7). Há ainda, nesse sentido, a percepção de que o setor de bebidas recebe muita influência das demandas da sociedade e por isso, precisa criar e inovar com produtos diferenciados com novos sabores, embalagens, ingredientes e características (BARROS, 2018).

Por fim, a estratégia especializada em processo que é aquela em que se busca otimizar processos e tecnologias para inovar (COSTA; FILHA; GUIDOLIN, 2011) foi encontrada somente nas três últimas cervejarias pesquisadas $(\mathrm{D}, \mathrm{E}$ e F).

Isso se dá por alguns motivos, tais como: são cervejarias maiores em produção e em capacidade de inovação, uma vez que se mostram como líderes de mercado. Por esse motivo, sugerimos denominar essas cervejarias especiais como líderes e as demais como imitadoras. A cervejaria E é uma das mais antigas de Belo Horizonte. Além de ter o produto difundido em todo o estado de Minas Gerais, conta com alta capacidade produtiva em litros, acesso à mãode-obra qualificada e ainda possui credibilidade no mercado.

Por fim, as cervejarias (D, E e F) foram as únicas capazes de adotar todas as estratégias de inovação presentes (passo a passo; orientada ao cliente e especializada em processo).

Na cervejaria D, verificou-se a presença de todas as estratégias de inovação. Tal fato pode ser vinculado à capacidade produtiva da cervejaria que está em expansão com adoção de novas tecnologias com máquinas e equipamentos. Além disso, essa cervejaria também realiza parcerias com fornecedores e clientes na busca por melhorar seus processos produtivos e entregar produtos com maior qualidade.

$\mathrm{Na}$ cervejaria E, esse fenômeno ocorre por ser uma das cervejarias mais antigas e tradicionais de Minas Gerais, com alta produção da bebida, investimentos em máquinas e 
equipamentos, cadeia produtiva desenvolvida, parcerias com fornecedores e clientes e presença em todo o estado.

Já na cervejaria $\mathrm{F}$ a presença de todas as estratégias de inovação pôde ser percebida pelo fato da cervejaria ter sido adquirida pela cervejaria transnacional $\mathrm{AB}$ InBev, fato que permite à cervejaria especial, o acesso à investimentos financeiros e a disponibilização de máquinas e equipamentos modernos e mão-de-obra qualificada.

Sobre as inovações realizadas na cervejaria, o cervejeiro F diz que

fazemos cervejas com diferentes tipos de garrafas, rolhas, rótulos chamativos e com sabores que são diferentes de tudo que o mercado apresenta. Tudo isso também para alcançar o consumidor que conhece o produto, que entende de cerveja e que paga por isso.

Essa cervejaria, de modo específico, ainda conta com um centro de inovação cervejeiro em que são criados e testados novos produtos com diferenciação e novas técnicas de produção (CARVALHO, MAIA, GODINHO, 2020).

Para além dos relatos apresentados, percebeu-se que as inovações nas cervejarias ocorrem por indução de diferentes variáveis, tais como os fatores organizacionais e econômicos. Além dos fatores sociais que contribuem para a ocorrência desse fenômeno.

As cervejarias com maior criação de inovações foram aquelas que apresentaram maior acesso à tecnologias, maior interação com os clientes e maior acesso à mão-de-obra especializada. Nas visitas às cervejarias D, E e F pudemos perceber essas características. Ainda nessa discussão, o fator econômico foi determinante para o surgimento de diferentes tipos de inovação e pelo emprego de todas as estratégias de inovação por essas cervejarias. Há, em todos os casos, maior dispêndio de recursos financeiros nessas cervejarias, uma vez que já são consolidadas no mercado mineiro e nacional, possuem, em um dos casos (cervejaria E) aporte financeiro de uma empresa transnacional, e conseguem maior acesso à financiamento e crédito para operacionalizar toda a produção.

Também chamou atenção dos pesquisadores os fatores sociais que serviram como determinantes para a indução das inovações nas cervejarias. Esse fator aqui foi chamado de "Rede Colaborativa Informal - RCI". Trata-se do diálogo e da cooperação existente entre os cervejeiros na busca por um mercado que seja unido e que consiga competir com as grandes cervejarias. Dentro dessa lógica, os cervejeiros colaboram entre si trocando receitas, contatos de fornecedores e organizando eventos entre eles. Desse modo, essas interações sociais presentes nas cervejarias também foram identificadas como um determinante da inovação.

Os resultados aqui encontrados mostram que as cervejarias especiais da RMBH são organizações inovadoras que para inovar e manter-se competitivas no mercado lançam mão de maneira concomitante das diferentes estratégias de inovação do setor de baixa tecnologia. Essas estratégias foram encontradas em um setor específico da economia, que não é intensivo em $\mathrm{P} \& \mathrm{D}$, mas que, a partir das evidências encontradas, apresentou-se inovador com a presença de diferentes tipos de inovações. Dessa maneira, essa pesquisa trouxe como contribuição o fato de descortinar as estratégias de inovação em um setor específico da economia, o setor de bebidas alcoólicas, em específico, o de cervejas especiais. Na próxima seção serão apresentadas as considerações finais que encerram a discussão aqui proposta.

\section{CONSIDRAÇÕES FINAIS}

A experiência das cervejarias especiais aqui estudada contribuiu para compreender como as estratégias de inovação ocorre nessas empresas. De modo geral, com as análises dos dados coletados, a pesquisa permitiu verificar que existem diferentes fatores organizacionais, econômicos, institucionais e sociais que atuam de maneira concomitante, na indução das estratégias de inovações dessas cervejarias.

As estratégias do setor de baixa-média tecnologia estão presentes. Entretanto, só as cervejarias D, E e F lançam mão de todas as estratégias concomitantemente (passo a passo, 
orientada ao cliente e especializada em processo). Isso ocorre por serem cervejarias maiores em faturamento e tamanho, o que provê maior acesso a matéria-prima, equipamentos, tecnologias e mão-de-obra especializada.

Todas as cervejarias investigadas servem-se das estratégias passo a passo e orientada ao cliente. Isso mostra que as cervejarias especiais da RMBH aqui estudadas apostam em inovações incrementais que englobam todas as estratégias de inovação do setor de média-baixa tecnologia. Os relatos captados nessa pesquisa também revelaram que existem inovações em todas essas cervejarias, todas com características incrementais.

Esse estudo também contribuiu para alavancar o uso de metodologias qualitativas nas pesquisas que versam sobre inovação tecnológica uma vez que se percebeu que existem fenômenos que podem ser observados nesse campo do conhecimento com a utilização de metodologias não tradicionais se comparadas às principais pesquisas da área, tal como a pesquisa de Inovação do IBGE ou às pesquisas realizadas de modo quantitativo ou qualitativo que são inspiradas nas indicações do Manual de Oslo. Lembra-se que esses tipos de pesquisa, embora importantes, são setoriais e não conseguem, por suas limitações, captar fenômenos específicos de inovação que podem ocorrer dentro das empresas. Outro aspecto importante a ser ressaltado é que o setor estudado não é intensivo em P\&D, por isso, para investigar as inovações nesse setor, sugere-se a utilização de metodologias diferentes das tradicionais já utilizadas.

Como limitações, esse estudo poderia ter abrangido outras cervejarias, uma vez que a região possui mais de 30 estabelecimentos registrados no Ministério da Agricultura e Abastecimento. Entretanto, durante a pesquisa, algumas cervejarias estavam em obras de expansão da capacidade produtiva e, tal fato, inviabilizou a coleta de dados. Além disso, outra intercorrência inviabilizou a expansão da coleta de dados, a pandemia de COVID-19.

Frente às limitações expostas e encontradas aqui, sugere-se que o escopo dessa pesquisa seja ampliado com um hall maior de cervejarias, buscando encontrar outras cervejarias líderes para verificar e entender as estratégias de inovação que são adotadas, assim como outras cervejarias imitadoras, na busca por também compreender quais estratégias de inovação essas adotam. E ainda, sugere-se que a pesquisa não se limite apenas às cervejarias mineiras ou da $\mathrm{RMBH}$, mas também as de outros estados líderes em quantidade de cervejarias especiais e produção, tais como São Paulo e Rio Grande do Sul.

\section{Agradecimentos}

O presente trabalho foi realizado com apoio da Fundação de Amparo à Pesquisa do Estado de Minas Gerais (FAPEMIG), do Instituto Federal de Educação, Ciência e Tecnologia do Norte de Minas Gerais (IFNMG) e do Conselho Nacional de Desenvolvimento Científico e Tecnológico (CNPq) por meio do processo 314360/2020-4. 


\section{REFERÊNCIAS}

ALMEIDA, S. W. de. Estudo da Inovação na Indústria Brasileira de Alimentos e Bebidas. Dissertação (Mestrado em Nutrição e Alimentos) - Universidade do Vale do Rio dos Sinos, Programa de Pós-Graduação em Nutrição e Alimentos, São Leopoldo (RS), 2014.

AYER, Flávia. Com 15 cervejarias artesanais, Grande BH se consolida como o 'cinturão da cevada' em MG. Estado de Minas - Economia. Disponível em: https://www.em.com.br/app/noticia/economia/2017/04/02/internas_economia,859102/cervejaartesanal-cresce-producao-em-minas-e-grande-bh.shtml. Acesso em: abr. 2018.

BACK, G. D. Inovação de produto sob a perspectiva da visão baseada em recursos: o caso das Microcervejarias (Dissertação). Universidade Caxias do sul. Programa de Pós-graduação em Administração. 2015.

BARROS, M. C. de. A Inovação na Indústria de Bebidas e o caso da Leão Alimentos e Bebidas. 2018. 95p. Dissertação (Mestrado) - Instituto de Ciências Biológicas, UFMG, Belo Horizonte, 2018.

BELTRAMELLI, M. Cervejas, brejas e birras: um guia completo para desmistificar a bebida mais popular do mundo. $2^{\mathrm{a}}$ ed. São Paulo: Leya, 2014.

CABRAS, I.; HIGGINS, D. M. Beer, brewing, and business history. Business History, p. 116, 2016.

CARVALHO, João Francisco Sarno. Uma análise das fontes indutoras de inovação nas cervejarias especiais da região metropolitana de Belo Horizonte. 2020. 152 f. Tese (Doutorado em Inovação Tecnológica e Biofarmacêutica) - Instituto de Ciências Exatas, Universidade Federal de Minas Gerais, 2020.

CARVALHO, João Francisco Sarno; MAIA, Ulisses Barros de Abreu; GODINHO, Carla Soares. Innovation management in the brewer market: the Wäls Madlab case study. RACEF Revista de Administração, Contabilidade e Economia da Fundace. v. 11, n. 1, p. 1-21, 2020.

CARVALHO, João Francisco Sarno; OLIVEIRA, João Leandro Cássio de; GODINHO, Carla Soares. A interdisciplinaridade como uma nova proposta para os estudos da ciência, tecnologia e inovação. Diálogos Interdisciplinares, v. 8, n.3, p. 1-18, 2019.

CERV Brasil - Associação Brasileira da Indústria da Cerveja. Dados do setor. Disponível em: http://www.cervbrasil.org.br/paginas/index.php?page=dados-do-setor. Acesso em: mai. 2021.

COSTA, A. C. R. da; FILHA, D. C. M.; GUIDOLIN, S. M. Inovação nos setores de baixa e média tecnologia. Disponível em: https://web.bndes.gov.br/bib/jspui/bitstream/1408/2521/2/A\%20BS\%2033\%20Inova\%C3\%A 7\%C3\%A3o\%20nos\%20setores\%20de\%20baixa\%20e\%20m\%C3\%A9dia\%20tecnologia_P.p df.Acesso em: jun. 2020.

CRUZ, J. M. M. Cerveja. In: FONSECA, M. M.; TEIXEIRA, J. A. Reactores Biológicos. Lisboa/Porto: Lidel, 2007, p. 277-305.

DOSI, G.; NELSON, R. R. Na introduction to evolutionary theories in economics. Journal of Evolutionary Economics, v. 4, n. 3, p. 153-172, 1994.

FERREIRA, R. H. Inovação em Cervejas Especiais na Região Metropolitana de Belo Horizonte. Dissertação: Mestrado Profissional em Administração. Faculdades Integradas Pedro Leopoldo, 2010. 
FREEMAN, C.; SOETE, L. A Economia da Inovação Industrial. Campinas, SP: Editora da Unicamp, 2008.

GIORGI, Victor Vargas. Cultos em cerveja: discursos sobre a cerveja artesanal no Brasil. Sociedade e Cultura, vol. 18, $\mathrm{n}^{\mathrm{o}}$. 1, enero-junio, p. 101-111, 2015.

GODOY, A. S. Pesquisa qualitativa: tipos fundamentais. Revista de Administração de empresas, v. 35, n. 3, p. 20-29, mai./jun., 1995.

HIRSCH-KREINSEN, H. Low-tech innovations. Industry \& Innovation, v. 15, n. 1, p. 1943, fev. 2008.

HIRSCH-KREINSEN, H; JACOBSON, D.; LAESTADIUS, S.; KEITH, S. Low-tech industries and the knowledge economy: state of the art and research challenges. Oslo: STEP Centre for Innovation Research, ago. 2003.

KLINE, S.; ROSENBERG, N. An overview of innovation. In: LANDAU, R.; ROSENBERG, N. (Orgs.). The positive sum strategy. Washington: National Academy of Press, 1986.

MANUAL, DE OSLO. Diretrizes para coleta e interpretação de dados sobre inovação. Publicação conjunta da OCDE e Eurostat. Versão Brasileira: Financiadora de Estudos e Projetos (Finep). Tradução de Flávia Gouveia, v. 3, 2005.

MARCUSSO, E. F.; MULlER, C. V. Anuário da Cerveja 2019. Disponível em: http://antigo.agricultura.gov.br/noticias/total-de-cervejarias-registradas-no-mapa-cresceu-36em-2019-e-chegou-a-1.209/anuariocervejaWEB.pdf. Acesso em: mai. 2020.

Anuário da Cerveja no Brasil 2018: Crescimento e Inovação. Disponível em: http://www.agricultura.gov.br/assuntos/inspecao/produtos-vegetal/pasta-publicacoesDIPOV/anuario-da-cerveja-no-brasil-2018. Acesso em: fev. 2019.

MORADO, R. Larousse da cerveja. São Paulo: Larousse do Brasil, 2009.

MORAES, Roque. Análise de conteúdo. Revista Educação, Porto Alegre, v. 22, n. 37, p. 732, 1999.

MORCEIRO, P. C. FORNARI, V. C. B.; GALVAO, L. GOMES, R. Por que não baixa tecnologia? Conference, Buenos Aires. Disponível em: https://www.researchgate.net/publication/301922156_POR_QUE_NAO_BAIXA_TECNOLO GIA. Acesso em: jun. 2020.

MORCEIRO, P. C.. Nova Classificação de Intensidade Tecnológica da OCDE e a Posição do Brasil. Temas de Economia Aplicada. 2019. Disponível em: http://www.econometrix.com.br/pdf/e8a49d0b18f54cbfee3b79e1738011ee9315b2d5.pdf\#pag e=8. Acesso em: jun. 2020 .

PAVITT, K. Sectoral patterns of technical change: towards a taxonomy and a theory. Research Policy, 13, 343-373. http://dx.doi.org/10.1016/0048-7333(84)90018-0, 1984.

PREFEITURA DE BELO HORIZONTE. Região Metropolitana de Belo Horizonte. Disponível em: http://gestaocompartilhada.pbh.gov.br/estrutura-territorial/regiaometropolitana-de-belo-horizonte. Acesso em: mar. 2017.

ROGERIO, B.M.; MORETTI, R.H. Produção de cerveja Pilsen com malte concentrado. Congresso Interno de Iniciação Científica. 16., Anais... Departamento de Tecnologia de Alimentos, UNICAMP, SP, Brasil, 24 a 25 set, 2008. 
SANTOS, S. de P. Os primórdios da cerveja no Brasil. São Paulo: Ateliê Editorial, 2003.

SAWHNEY, M., WOLCOTT, R. C., ARRONIZ, I. The 12 different ways for companies to innovate. MIT Sloan Management Review, v. 47, n. 3, 75-81, 2006.

TIDD, J.; BESSANT, J. Gestão da Inovação. 5. ed. Porto Alegre: Bookman, 2015.

TIDD, J.; BESSANT, J. R.; PAVITT, K. Managing innovation: integrating technological, market and organizational change. Chichester: Wiley, 2005.

TIRONI, L. F.; CRUZ, B. de O. Inovação Incremental ou Radical: Há Motivos para Diferenciar? Uma Abordagem com Dados da PINTEC. Texto para Discussão no 1360. Brasília, IPEA, 2008.

TORNIC, H. E. Da cevada a bebida. Revista Alimentos e Tecnologia, v. 1, n. 7, p. 11-16, 1986.

TORO-GONZÁlEZ, D. The Beer Industry in Latin America. AAWE WORKING PAPER. No. 177. 2015.

TSCHOPE, E. C. Microcervejarias e Cervejarias - A História, a Arte e a Tecnologia. São Paulo: Editora Aden, 2001.

TUNZELMANN V. N.; ACHA, V. "Innovation in 'low-tech' industries." In: J. FAGERBERG, D. MOWERY e R. R. NELSON (Eds): The Oxford Handbook of Innovation, pp. 407-432. Oxford: Oxford University Press, 2005.

YIN, R. K. Pesquisa qualitativa: do início ao fim. tradução: Daniel Bueno; revisão técnica: Dirceu da Silva. - Porto Alegre: Penso, 2016. 